\title{
2020 European Thyroid Association Clinical Practice Guideline for the Use of Image-Guided Ablation in Benign Thyroid Nodules
}

\author{
Enrico Papini $^{a}$ Hervé Monpeyssen $^{b}$ Andrea Frasoldatic ${ }^{c}$ Laszlo Hegedüs $^{d}$ \\ ${ }^{a}$ Department of Endocrinology and Metabolism, Regina Apostolorum Hospital, Rome, Italy; ${ }^{b}$ Thyroid Unit, American \\ Hospital, Paris, France; ' Department of Endocrinology and Metabolism, Arcispedale Santa Maria Nuova IRCCS-ASL, \\ Reggio Emilia, Italy; ${ }^{\mathrm{d}}$ Department of Endocrinology and Metabolism, Odense University Hospital, Odense, Denmark
}

\section{Keywords}

Thyroid nodule $\cdot$ Thermoablation - Laser ablation . Radiofrequency · High-intensity focused ultrasound . Microwaves · European Thyroid Association

\begin{abstract}
Standard therapeutic approaches for benign thyroid lesions that warrant intervention are surgery for cold and either surgery or radioiodine for autonomously functioning thyroid nodules (AFTN). Image-guided thermal ablation (TA) procedures are increasingly proposed as therapy options for selected clinical conditions. Due to mounting scientific evidence and widening availability, ETA considered it appropriate to develop guidelines for the use of TA in adult patients. TA procedures are well tolerated, but a dedicated training of the operators is required and information on possible complications needs to be shared with the patients. The following factors should be considered when weighing between observation, surgery, and TA for benign thyroid nodules. In solid non-hyperfunctioning nodules, TA induces a decrease in thyroid nodule volume, paralleled by improvement in symptoms. Nodule re-growth is possible over time and may necessitate repeat treatment, or surgery, in a dialogue with the patient. In AFTN, radioactive iodine is the first-line treatment, but TA may be considered in young patients with small AFTN due to higher probability of restoring normal thyroid function and avoidance of irradiation. In
\end{abstract}

cystic nodules, ethanol ablation (EA) is the most effective and least expensive treatment. TA may be considered for cystic lesions that relapse after EA or have a significant residual solid component following drainage and EA. TA should be restricted to benign lesions that cause symptoms or cosmetic concern. Presently, laser and radiofrequency ablation are the most thoroughly assessed techniques, with similar satisfactory clinical results. Microwaves and high-intensity focused ultrasound therapy options remain to be fully evaluated.

(C) 2020 European Thyroid Association Published by S. Karger AG, Basel

\section{Scope of the Document}

Thyroid nodules are common in the adult population with a prevalence at ultrasound (US) examination of up to $50 \%$ in adult females and $30 \%$ in males [1-3]. Most lesions are cytologically benign and neither cause local symptoms nor warrant treatment. However, a non-negligible number of patients experience pressure symptoms, complain of cosmetic concerns, or develop subclinical or overt hyperthyroidism due to an autonomously functioning thyroid nodule (AFTN) [1-3]. The above leads, in European countries, to thousands of patients undergoing surgical treatment despite evidence of a benign nodule, most of whom have not been offered any non-surgical therapy options $[4,5]$.
Laszlo Hegedüs

Department of Endocrinology and Metabolism Odense University Hospital

Kløvervænget 6, 5th Floor, DK-5000 Odense (Denmark)

laszlo.hegedus@ rsyd.dk 
In such cases, initially, ethanol ablation (EA) and, then, image-guided thermal ablation (TA) procedures, usually performed under US guidance, have been proposed as non-surgical treatment options for around 3 decades. Currently, due to their predictable tissue destruction, TA procedures have superseded, with the exception of pure cysts, the use of EA for thyroid lesions [6-8]. TA, based on the irreversible nodule damage induced by increase in tissue temperature [6-8], selectively destroys a predictable area of the nodule, while sparing the surrounding normal tissue. TA techniques are considered cost- and risk-effective in accomplishing the patients' demand for shrinking benign nodules and improving local symptoms less invasively than with surgery and, most importantly, generally without causing hypothyroidism. These non-surgical techniques are implemented over large parts of Europe and the Far East and are used in several thyroid centers. Despite this, there is little guidance, besides a few national consensus papers [9-12], on the appropriate use of TA in clinical practice. While US-guided diagnostic procedures are widely employed by European endocrinologists, routine use of US-guided therapeutic procedures is still limited to specialized thyroid centers [13]. The ETA survey on minimally invasive treatments demonstrated that, besides the limited access to dedicated training opportunities, the major cause of this only partial implementation was the absence of official statements about their use and indications from the Scientific Societies [13]. For these reasons, the present document offers a list of recommendations for a state-ofthe-art use of TA in the management of benign thyroid lesions.

In order to compensate for current non-homogeneous data reporting and trial terminology, the text has been standardized according to the "Image-Guided Thyroid Ablation Procedures: Proposal for Standardization of Terminology and Reporting Criteria" recommendations [14]. In view of this being an ETA guideline, the focus has been on the highest possible level of evidence derived from studies carried out in a European setting.

These guidelines address the optimization of the use of innovative therapeutic tools in clinical management of benign thyroid nodules. They address the vast majority of the thyroid nodule population but are not intended for pediatric cases. While TA is covered, in extenso, EA and radioactive iodine ablation procedures for thyroid nodules are only mentioned in passing. How the diagnosis of a benign nodule is reached is not described in detail; for this, we refer to the pertinent thyroid nodule guidelines $[15,16]$. The use of TA in malignant nod-

ETA Image-Guided Thyroid Ablation Guideline ules, whether primary or metastatic, is not part of this document.

Importantly, the recommendations always need to take local legislation, clinical setting, medical expertise, available technical resources, and patient preference into consideration.

The ETA GL recommendations for image-guided thyroid ablation are summarized in Table 1.

\section{Methodology for Grading of Evidence and Strength of Recommendations}

The Executive Committee of the European Thyroid Association (ETA) commissioned development of this guideline. In consultation with the Guideline Board of the ETA, a task force led by a chairperson (L.H.) was assembled. This team of European clinicians authored the present article. Selection to the panel was based on clinical experience, scholarly approach, being an ETA member, and willingness to participate. The relevant literature was taken into consideration using a systematic PubMed search. We employed an evidence-based approach and incorporated both the knowledge and the practical experience of the panelists to develop the manuscript and the specific recommendations. The Grading of Recommendations, Assessment, Development, and Evaluation (GRADE) system [17], was used when rating the strength of the recommendations and the quality of evidence behind each of these.

In accordance with previous guidelines, we used the following coding system: (a) strong recommendation indicated by 1 , and (b) weak recommendation, or suggestion, indicated by 2 . The evidence grading is given as follows: very-low-quality (ØООО), low-quality ( ØØОО),

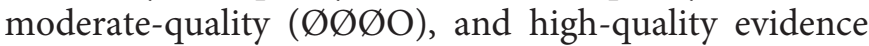

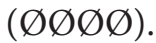

Following discussions and after the task force had reached consensus, the draft was sent to the Guideline Board for comments and thereafter posted on the ETA website for 4 weeks for critical evaluation by the ETA members. All received comments were evaluated by the guideline team, and the resulting changes were incorporated into the final document.

Recommendation 1. In adult patients with benign thyroid nodules that cause pressure symptoms and/or cosmetic concerns and decline surgery, image-guided TA should be considered as a costand risk-effective alternative option to surgical treatment or observation alone $(1, \varnothing \varnothing \bigcirc)$.

Recommendation 2. We recommend against the use of TA for asymptomatic lesions $(1, \varnothing \varnothing \emptyset О)$. 
Table 1. Summary of recommendations

Recommendation 1 In adult patients with benign thyroid nodules that cause pressure symptoms and/or cosmetic concerns and decline surgery, image-guided thermal ablation (TA) should be considered as a cost- and risk-effective alternative option to surgical treatment or observation alone $(1, \varnothing \varnothing \mathrm{OO})$

Recommendation 2 We recommend against the use of TA for asymptomatic lesions $(1, \varnothing \varnothing \varnothing \mathrm{O})$

Recommendation 3 Before TA of thyroid lesions, a benign cytological diagnosis is needed; a repeat FNA is suggested for cytologically benign nodules with the exception of spongiform nodules and pure cystic lesions (EU-TIRADS Class 2); we recommend against TA for nodules with high-risk US features (EU-TIRADS Class 5; $1, \varnothing \varnothing \varnothing O$ )

Recommendation $4 \quad$ Patients should be carefully informed before the procedure, orally and in writing, about the TA treatment options, their potential efficacy and side effects, the therapeutic alternatives, and the necessity of being compliant $(1, \varnothing \mathrm{OOO})$

Recommendation 5 Before the TA procedure, thyroid and vocal cord function, comorbidities, and contraindications to TA treatment should be evaluated; laryngoscopy is recommended in patients with hoarseness, previous neck surgery, or with nodules close to critical structures ("danger areas"; 1, ØØОО)

Recommendation $6 \quad$ Local subcutaneous and pericapsular anesthesia is recommended before TA procedures; Mild conscious sedation may be considered, especially in case of HIFU treatment $(1, \varnothing \varnothing \mathrm{OO})$

Recommendation $7 \quad$ At the end of the procedure, clinical and US evaluation is recommended in order to rule out potential early adverse effects and define the extent of the ablated area; patients should be instructed to present for clinical and US assessment if severe pain, local swelling, or fever occur within the first week after TA $(1, \varnothing \varnothing \mathrm{OO})$

Recommendation 8 Early-term (e.g., 3 months) and intermediate-term (e.g., 6 and 12 months) clinical, biochemical, and US evaluations are recommended; long-term follow-up monitoring is suggested, in the absence of symptoms every $1-2$ years, in order to reveal regrowth $(1, \varnothing \varnothing \bigcirc)$

Recommendation 9 Based on direct comparison studies, and balance between efficacy and side effects, LTA and RFA are recommended as the first-line TA treatment modalities $(1, \varnothing \varnothing \varnothing \mathrm{O})$

Recommendation 10 Based on studies to date, MWA should at present be considered a second-line TA procedure in patients who are not suitable for or decline other TA procedures, or for participants in protocolled clinical studies $(1, \varnothing \varnothing \bigcirc 0)$

Recommendation 11 Based on its lower efficacy, higher cost, and limited reported trial evidence, as compared to RFA and LTA, HIFU should be considered only for selected nodules in patients who are not suitable for or decline other TA procedures, and for participants in protocolled studies $(1, \varnothing \varnothing \mathrm{OO})$

Recommendation 12 In multinodular goiters, due to lack of evidence of efficacy and the expected need of repeat treatment, TA should be restricted to patients with a well-defined dominant nodule or those who are not candidates for thyroid surgery or radioactive iodine treatment, as a palliative therapy option $(1, \varnothing \varnothing \mathrm{\varnothing O})$

Recommendation 13 Because of higher cost and complexity, as compared to aspiration and EA, TA procedures are not recommended as a first line treatment for pure or dominantly cystic thyroid lesions $(1, \varnothing \varnothing \varnothing \mathrm{O})$

Recommendation $14 \quad$ LTA and RFA should be considered therapeutic options for cystic lesions that relapse after EA and for those that would remain symptomatic due to a large residual solid component $(1, \varnothing \varnothing \varnothing \mathrm{O})$

Recommendation 15 We recommend against TA as first-line treatment for large AFTN; due to the low rate of restoration of normal thyroid function, TA should be considered only for patients who decline or are not candidates for RAI therapy or surgery $(1, \varnothing \varnothing \varnothing O)$

Recommendation 16 TA should be considered in young patients with small AFTN and incomplete suppression of perinodular thyroid tissue due to the higher probability of normalization of thyroid function and the advantage of avoiding irradiation and restricting risk of late hypothyroidism $(1, \varnothing \varnothing \bigcirc \mathrm{O})$

Recommendation 17 Treatment with a combination of LTA or RFA and RAI may be considered in selected patients with large AFTN that cause local pressure symptoms in order to achieve a more rapid volume reduction and use of a lower RAI activity $(2, \varnothing \varnothing \mathrm{OO})$

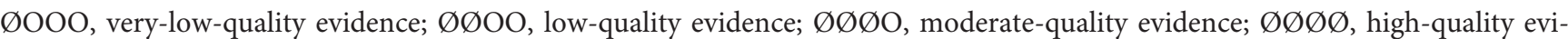
dence. 
Table 2. Modalities, technical characteristics, and estimated costs of thermoablation treatment

\begin{tabular}{|c|c|c|c|c|}
\hline Disposables, G & 21 & $15-18$ & & $14-16$ \\
\hline Mean power, $\mathrm{W}$ & 3-7 per fiber & $35-60$ & $30-40$ & $30-50$ \\
\hline Duration, min & $15-30$ & $15-40$ & $45-60$ & $10-20$ \\
\hline \multicolumn{5}{|l|}{ Average price in EUR (excl. tax) } \\
\hline Device & 30,000 & $17,000-25,000$ & $>250,000$ & $20,000-25,000$ \\
\hline Disposables & 1 fiber $\sim 300-500$ & Electrode 700-900 & Kit $\sim 500$ & Antenna $1,000-1,250$ \\
\hline $\begin{array}{l}\text { Contraindications, besides clotting } \\
\text { disorders }\end{array}$ & & $\begin{array}{l}\text { Pacemaker } \\
\text { Pregnancy }\end{array}$ & Cystic component & \\
\hline Comments & $\begin{array}{l}\text { Two operators } \\
\text { No need for moving-shot }\end{array}$ & $\begin{array}{l}\text { Experience in moving-shot } \\
\text { or multiple overlapping } \\
\text { technique }\end{array}$ & $\begin{array}{l}\text { Management of move- } \\
\text { ments and pain } \\
\text { Long duration }\end{array}$ & $\begin{array}{l}\text { Limited experience in } \\
\text { Europe }\end{array}$ \\
\hline
\end{tabular}

G, gauge; RFA, radiofrequency; HIFU, high-intensity focused ultrasound, MWA, microwaves.

\section{Thermal Treatment: Currently Available Techniques}

Among the currently available TA techniques for benign thyroid nodules, laser thermal ablation (LTA), radiofrequency ablation (RFA), microwave ablation (MWA), and high-intensity focused ultrasound (HIFU) have been tested in clinical practice and will be addressed in the present document. The devices employed by the different technologies are also defined as applicators [14].

\section{Laser}

Laser is a focused beam of light energy, usually generated by a diode or a Nd:YAG source, delivered through an optical fiber into the target tissue [6-8]. In LTA of thyroid nodules, $1-4$ optical fibers are inserted at a $10-\mathrm{mm}$ distance from each other, along the longitudinal axis or with a trans-isthmic approach, into the target nodule through thin and flexible 21 -gauge $(G)$ needles. The heatinduced changes of the tissue are visible through the appearance of hyperechoic signals due to the formation of gas microbubbles. The backward re-positioning ("pull back") of the fiberoptics during the procedure allows the destruction of large portions of the thyroid nodule. The mean applied power of LTA is the lowest between the various TA techniques. The procedure is performed in an outpatient setting and requires $15-30 \mathrm{~min}$ [6-8].

In Europe, the cost of a disposable kit with a single fiber for LTA ranges from EUR 300 to 500. A diode laser source, without the US equipment, costs around EUR
30,000. Importantly, the price of laser and of the other TA devices may differ widely between the different European countries (Table 2).

\section{Radiofrequency}

An electric field, produced by a radiofrequency generator connected to an internally cooled electrode needle, leads to frictional agitation at the ionic level and to heat generation (Joule effect). Monopolar electrodes, with collecting pads, and bipolar devices, without pads, are available $[6,10,18]$. Shorter $(7-10 \mathrm{~cm}$ length) and thinner (17-19 G) devices, appropriate for use in the neck region, have substituted multi-hook expandable needles. The electrode is introduced under US guidance into the target nodule, and a continuous repositioning of the applicator ("moving shot" or "multiple overlapping shot" technique) results in an ellipsoidal necrotic area [19]. As with LTA, the appearance of hyperechoic signals close to the electrode tip indicates the development of tissue changes, while a steep rise in tissue impedance demonstrates the achievement of tissue necrosis $[6,10,18]$.

In Europe, the cost of a disposable applicator ranges from EUR 500 to 1,000. The treatment is performed in an outpatient clinic setting and requires 15-40 min (Table 2).

\section{Microwaves}

The equipment consists of a microwave generator, a flexible low-loss coaxial cable, and an internally cooled antenna corresponding to a $14-$ to $16-G$ needle [20-22]. 
Smaller and less invasive MWA applicators are currently under development. The antenna is inserted into the nodule under US guidance, usually using a trans-isthmic approach, and the procedure is then performed according to a "moving-shot technique" until hyperechoic changes cover the entire nodule or a large part of it [20-22].

The cost of MWA applicators is about EUR 600 in Europe. Treatment is performed on an outpatient basis and lasts 10-20 min (Table 2).

\section{High-Intensity Focused Ultrasound}

With HIFU, sparing of extranodular tissues is achieved by a computer-assisted planning of the procedure [23, 24].

Heat is generated by the conversion of acoustic into thermal energy. A US diagnostic receiver and a generator of US waves are combined in a single cooled probe. A computerized mapping of the targeted tissue on the US screen provides safety margins for the skin, trachea and large neck vessels $[23,24]$. The US beam is automatically delivered to the target tissue through multiple shots, and the procedure is performed without needle insertions. Repositioning of the patient is needed when patient motions are detected by a laser control, in order to avoid treatment of critical areas $[23,24]$. The cost of a HIFU machine is over EUR 250,000, and the cost of disposables is around EUR 500. The procedure is performed in an outpatient setting, and treatment duration ranges from 40 to $60 \mathrm{~min}$, but large-size $(>5 \mathrm{~cm}$ ) nodules usually require multiple treatments (Table 2).

\section{Patient Eligibility and Preparation}

A benign cytological diagnosis is needed before planning TA of thyroid nodules, in order to minimize the risk of overlooking malignant lesions and thereby postponing their treatment. Thus, confirmation with a repeat FNA is appropriate in case of cytologically benign lesions, because follicular tumors and follicular variants of papillary thyroid carcinoma may not exhibit high-risk sonographic findings $[25,26]$ and have a non-negligible risk of false negative cytology $[27,28]$. Repeat FNA may be omitted in cytologically benign spongiform and pure cystic lesions (EU-TIRADS class 2) [15]. TA should never be performed on nodules with high-risk US features (EU-TIRADS Class 5) due to their considerable risk of harboring malignancy $[15,29]$. Since medullary thyroid cancer may not display suspicious sonographic features or unambiguous cytological findings, a single calcitonin determina- tion should be considered, together with TSH, in the initial biochemical evaluation $[2,11]$.

The treatment of asymptomatic lesions is discouraged, implying that TA should be restricted to benign lesions that cause local pressure symptoms or cosmetic concerns. Defining a nodule volume cut-off for offering TA is not straightforward because symptoms and cosmetic problems are influenced by the location of the thyroid lesions and the cervical circumference, in addition to a number of factors which cannot be objectively assessed $[1,10,26]$. Female patients and subjects with a thin neck may present early cosmetic concerns, and the majority of subjects with nodules $>30 \mathrm{~mm}$, especially if in the isthmus area, may complain of pressure symptoms [30]. Thus, partly in accordance with other guidelines [10], TA should be mainly considered for patients with nodules with a maximum diameter $\geq 30 \mathrm{~mm}$ that keep growing steadily during US follow-up and who start complaining of local discomfort. In patients with compressive multinodular goiter, TA should not be used as a substitute for surgery due to the inadequate efficacy in such cases and the need of multiple treatments. In these patients, a careful evaluation with CT or MR imaging should be performed to rule out the presence of intra-thoracic extension or potentially threatening compression of the vital structures [31]. In these cases, if used at all, TA should be restricted to patients with a dominant nodule who are not candidates for thyroid surgery, as a palliative therapy option $[11,14,20]$. Vocal cord function should be carefully considered before TA and laryngoscopic examination is warranted in patients with hoarseness, previous thyroid surgery, or with nodules close to the trachea or nerve structures [32]. After obtaining a thyroid function status, a dedicated US examination should be performed by the operator to confirm the indication for therapy, to exclude potential anatomic contraindications, and to plan the procedure. In case of hyperfunctioning thyroid nodules, hyperthyroidism should primarily be controlled with antithyroid drugs, and the advantages and disadvantages of radioiodine (RAI) treatment should be considered and discussed with the patient [33]. Graves' disease and toxic multinodular goiter are not suitable for TA procedures.

Clotting disorders, relevant comorbidities, and pregnancy status should be evaluated before TA treatment.

The patient needs to be carefully informed, orally and in writing, about:

- The various available management options, including observation, TA or surgery, and their respective advantages and limitations

- The modalities of TA treatment 
- The necessary compliance during the procedure

- The potential complications

- The expected decrease in nodule size, usually not associated with complete disappearance

- The possible regrowth over time with need of additional TA or surgery

- The need of long-term follow-up.

Recommendation 3. Before TA of thyroid lesions, a benign cytological diagnosis is needed. A repeat FNA is suggested for cytologically benign nodules with the exception of spongiform nodules and pure cystic lesions (EU-TIRADS Class 2). A calcitonin determination should also be considered. We recommend against TA for nodules with high-risk US features (EU-TIRADS Class 5) (1, ØØО).

Recommendation 4. Patients should be carefully informed before the procedure, orally and in writing, about the TA treatment options, their potential efficacy and side-effects, the therapeutic alternatives, and the necessity of being compliant (1, ØООO).

Recommendation 5. Before the TA procedure, thyroid and vocal cord function, comorbidities, and contraindications to TA treatment should be evaluated. Laryngoscopy is recommended in patients with hoarseness, previous neck surgery, or with nodules close to critical structures ("danger areas") (1, ØØОО).

\section{Procedure and Post-Procedural Management}

\section{Procedure}

The operators performing thyroid TA need appropriate experience in cervical US anatomy and US-guided diagnostic procedures and a dedicated training in imageguided therapeutic procedures.

During the TA procedure, frequent swallowing and head movements should be avoided. Hence, a mild conscious sedation (e.g., midazolam, 1-3 mg intravenously) may be helpful for keeping the patient relaxed throughout the procedure [9-12]. Local subcutaneous and pericapsular anesthesia is usually recommended when the TA technique requires large bore needles; in case of HIFU, although no invasive devices are required, local anesthesia may help diminish the pain caused by the mechanical injury to the skin and thyroid capsule by the US beam [9$11,18,19,23,24]$. Local anesthesia is usually performed by injecting $2 \%$ lidocaine, or mepivacaine solution, into the skin, neck muscles, and thyroid capsule along the expected needle tract. Monitoring of blood pressure, heart rate, and $\mathrm{pO} 2$ is required and is mandatory in case of conscious sedation [10-12].

Real-time US monitoring of the device's position during the TA procedure is strictly reinforced $[6-8,10,18-$ $21]$. Especially for nodules located close to the thyroid capsule, trachea and/or carotid artery, attention should be paid to preventing damage to the vital neck structures. In selected cases, local infusion of saline, or $5 \%$ glucose, solution forming a liquid barrier of at least $5 \mathrm{~mm}$ is required to isolate the target area from nearby critical structures [34]. Patients should be asked to communicate the onset of neck pain, which usually indicates heating of the thyroid capsule and requires discontinuation of treatment followed by repositioning of the TA applicator.

With HIFU, sparing of extranodular tissues is achieved by a computer-assisted planning of the procedure $[23$, 24].

\section{Post-Procedural Management and Follow-Up}

Mild compression of the neck with an ice pack may be useful for preventing local bleeding and thermal injury to the skin. After treatment, clinical and US evaluation is needed for detection of potential early adverse effects of the procedure (e.g., hematoma, burns, or damage to the thyroid capsule) and the assessment of the area of ablation. The treated area appears as a mildly hypoechoic and inhomogeneous zone, with scattered hyperechoic spots due to tissue vaporization $[7,10]$. Color-Doppler mapping improves defining the treated area, which appears as devoid of vascular signals. Contrast-enhanced US provides a more accurate assessment of the loss of small vessel signals and better depicts the incompletely treated peripheral areas [14, 35-40]. Notably, in a few European countries, thyroid nodular disease is not among the licensed indications for the use of US contrast agents.

After the procedure an anti-inflammatory (e.g., ketoprofen $100 \mathrm{mg}$ ) may be given parenterally in case of pain, followed by a painkiller given orally (e.g., paracetamol $1,000 \mathrm{mg}$ twice/day) during the following $24 \mathrm{~h}$. Patients should be instructed to present for clinical and US assessment in case of severe pain, local swelling, or fever occurring within the first week following TA [12].

Clinical trials have reported varying schedules for clinical and US short- and long-term monitoring [9-12]. Clinical, biochemical (with at least TSH determination), and US examinations are recommended as follows: (a) early: at 3 months, for assessment of initial effects of TA and thyroid function analysis; (b) intermediate: at 6 and 12 months, as above, for the assessment of nodule volume reduction and presence of remaining viable areas, because the maximum nodule shrinkage is nearly always achieved by this time. Subsequent US monitoring on a 1- to 2-year basis is useful to evaluate further nodule volume and structural changes [41-45]. Prolonged regular biochemical follow-up is generally not warranted for non-hyperfunctioning lesions, while protracted thyroid 
function monitoring is needed for AFTN. Long-term US follow-up is appropriate because part of the treated lesions regrow after 3-5 years and need additional TA or surgery [46-48]. Different criteria have been used to define nodule regrowth after TA, resulting in a variable 3 -year recurrence rate that approximately ranges from 5.0 to $24.0 \%$. Currently, regrowth after treatment should be defined as a nodule volume increase $>50 \%$ over the smallest recorded volume $[11,12,14]$. Main predictive factors for recurrence appear to be large initial size, functional autonomy, low applied energy, and incomplete ablation of the marginal areas of the nodules [36-38]. Therefore, during follow-up, demonstration of initial regrowth in untreated peripheral areas should prompt a second targeted TA to prevent further volume increase and recurrence of symptoms over time [39]. Notably, a repeat cytological assessment should be considered before retreatment, as nodule regrowth could be a potential sign of overlooked malignancy $[11,28]$.

Physicians who perform thyroid US examinations during follow-up after TA procedures should be aware of the timing and characteristics of structural modifications induced by the intervention. This is to avoid misinterpretations of late, potentially worrisome, morphological changes (e.g., development of a hypoechoic lesion with intranodular calcifications) [12].

Recommendation 6. Local subcutaneous and pericapsular anesthesia is recommended before TA procedures. Mild conscious sedation may be considered, especially in case of HIFU treatment (1, $\varnothing \varnothing ० 0)$.

Recommendation 7. At the end of the procedure, clinical and US evaluation is recommended in order to rule out potential early adverse effects and define the extent of the ablated area. Patients should be instructed to present for clinical and US assessment if severe pain, local swelling, or fever occur within the first week after TA $(1, \varnothing \varnothing О О)$.

Recommendation 8. Early-term (e.g., 3 months) and intermediate-term (e.g., 6 and 12 months) clinical, biochemical, and US evaluations are recommended. Long-term follow-up monitoring is suggested, in the absence of symptoms every 1-2 years, in order to reveal regrowth $(1, \varnothing \varnothing \mathrm{\varnothing O})$.

\section{Thyroid Phenotypes and TA Outcomes}

When interpreting the data, whether using the same or different TA techniques, major limitations are due to the inhomogeneity of the studies concerning a number of parameters (e.g., patient and nodule selection, description of technique efficacy [generally defined for benign solid nodules as a volumetric reduction $\geq 50 \%$ of the initial nodule volume], modality of treatment and follow-up, as well as treatment variables, including applied energy per $\mathrm{mL}$ of nodule tissue) $[12,14]$.

\section{Solid Nodules}

Laser

Short- and long-term technique efficacy of LTA have been documented in a number of single-center randomized trials [41, 42], and confirmed by a multicenter randomized study of 101 patients showing a 59\% mean volume reduction at 12 months [43]. A multicenter study of 1,531 patients reported a $72 \%$ mean volume reduction at 12 months [44], and a 12-month trial demonstrated an $84 \%$ mean volume reduction [45]. LTA efficacy seems stable, with a $51-58 \%$ mean volume reduction at 36 months $[27,43]$. Accordingly, only a minority (5-9\%) of treated nodules exhibit significant re-growth within a 3-year follow-up [43-46]. The results of LTA in benign non-functioning thyroid nodules have been synthesized in a recent meta-analysis which reported a $48,52,45$, and $44 \%$ mean volume reduction rate (VRR) at $6,12,24$, and 36 months, respectively [49].

As for the other TA techniques, nodule structure (completely vs. mostly solid, and well delineated vs. coalescent) may influence long-term results but is not systematically reported in clinical trials. Outcomes are generally described as more favorable in spongiform and mixed than in completely solid nodules [48].

LTA results in amelioration of cosmetic concerns and local symptoms in the majority of patients. In a prospective multicenter study, only $8 \%$ of patients still complained of pressure symptoms at their final evaluation, compared to $38 \%$ at baseline [43]. Similarly, in a randomized study, symptom improvement was achieved in $81 \%$ of patients treated by LTA versus 0 and $13 \%$ in the placebo- and LT4-treated groups, respectively [42]. In addition, in a retrospective multicenter study, the rate of pressure and cosmetic symptom relief after LTA was 48 and $86 \%$, respectively, versus 10 and $8 \%$, respectively, in control subjects [44].

Major complications, defined as unexpected events which may result in severe morbidity and disability increasing the level of assistance $[14,50]$, are rarely observed after LTA. In a large multicenter study, a $0.5 \%$ rate of major complications was reported, with temporary vocal cord palsy documented in 8 out of 1,531 patients [44]. Notably, in 6 of the 8 patients, the target nodule was located in a "danger area," close to the infero-medial portion of the thyroid lobe. Therefore, this paratracheal thyroid zone should be carefully avoided in case of benign lesions [44]. Minor complications (sub-capsular and 
peri-thyroidal hematomas and skin burns) were reported in $0.5 \%$ of patients. A single case of "nodule rupture" has been described but pseudocystic transformation and fasciitis represent more frequent complications and need to be better defined [44]. The tolerability of LTA seems good, although self-limiting side effects (mostly transient neck pain) have occurred in $12-30 \%$ of LTA sessions. Post-treatment, thyroid function abnormalities have only been anecdotally reported.

Data from validated benign thyroid disease-specific questionnaires, such as the ThyPRO [51, 52] assessing quality of life (QoL) changes are still limited. In a prospective study, both a visual analogue scale, which rated discomfort in the neck, and a validated 13-scale QoL questionnaire demonstrated significant improvement after LTA [53].

\section{Radiofrequency}

RFA is an effective TA treatment for thyroid nodules $[54,55]$. Mean volume reduction in randomized controlled trials, which did not always differentiate complex from solid nodules, ranged from 69 to $78 \%$ at 12 -month follow-up $[56,57]$, and a 5-year retrospective study demonstrated long-term clinical efficacy with a median $67 \%$ volume reduction [58]. In the previously quoted meta-analysis, RFA was associated with a 68,75 , and $87 \%$ mean VRR at 6,12 , and 24 months, respectively [49]. As a general rule, the smaller the treated nodule the higher the volume reduction ( $78-82 \%$ in $\leq 10$ - to $12-\mathrm{mL}$ nodules vs. $62-65 \%$ in $>20$ - to 30 -mL nodules) [56, 57]. As tissue structure affects the alternating current flow, compact tissues are more resistant than soft tissues and, as for LTA, spongiform and mixed nodules respond better to RFA than solid lesions [58, 59]. RFA treatment has been shown to ameliorate pressure as well as cosmetic symptom scores $[58,60]$.

In a retrospective multicenter study of 1,543 nodules, major complications were recorded in $1.4 \%$ of patients, 15 of whom complained of voice changes [61]. A metaanalysis provided similar results, with a $1.3 \%$ rate of major complications in a population of over 2,400 patients; again, voice changes were permanent only in $4(0.16 \%)$ of the treated patients [62]. A rather rare complication has been "nodule rupture," characterized by breakdown of the anterior thyroid capsule and formation of a fluid collection in the anterior neck, which may potentially require surgical drainage [61]. Horner's syndrome and spinal accessory nerve injury are extremely rare but have been reported. Hematomas, skin burns, persistent pain, vaso-vagal reactions, and vomiting are the minor complications or side effects described $[61,62]$.

ETA Image-Guided Thyroid Ablation Guideline
Data on patient satisfaction are limited, and head-tohead prospective studies of RFA versus surgical treatment are lacking. In a cross-sectional study, patients were significantly more satisfied with cosmetic results in the RFAtreated than in the surgical group, but no significant differences were demonstrated in overall satisfaction [63]. In a study of 404 patients, RFA resulted in significantly better HRQoL scores than thyroidectomy, and qualityadjusted life years following RFA were higher than following surgery [64].

\section{Microwave Ablation}

High-quality evidence using MWA is limited. Retrospective studies describe a 74.6-90.0\% mean volume reduction after 1 year [22], and in 2 meta-analyses volume reduction was $74 \%$ at 6 months and $89 \%$ at 12 -month follow-up $[65,66]$. However, in a prospective study comparing the performance of cooled versus uncooled MWA applicators, the mean reduction rates at 3 months were only 40 and $29 \%$, respectively [67]. As with LTA and RFA, this variability in technique efficacy could be due to the heterogeneous structure of the nodules of the patients enrolled in the studies. Currently, MWA appears associated with a higher risk of major and minor complications than LTA and RFA, probably due to a poorer control of the applied energy and to the larger bore of the applicators [66].

A randomized trial in 52 patients demonstrated that MWA was followed by better general health and mental scores than thyroid surgery at 12 and 24 months [68]. In another randomized trial in 108 patients, MWA resulted in a lower visual analogue scale post-procedural pain score, and lower mean cortisol level, as a measure of stress, compared to surgery [69].

\section{High-Intensity Focused Ultrasound}

Controlled studies using HIFU are few, are from few institutions, and offer no data from prospective randomized trials. In a 2017 review [70], which included 6 retrospective and prospective studies with a follow-up ranging from 3 to 12 months, the mean volume reduction after HIFU ranged from 48.8 to $68.8 \%$. Similar results were obtained in 2 retrospective non-controlled studies reporting a $43 \%$ and a $70 \%$ volume decrease at 24 -month follow-up $[71,72]$. An inverse correlation between the initial nodule volume and the percentage shrinkage of the lesion was reported, and a $>50 \%$ volume decrease was seen only in small-size $(\leq 3.0 \mathrm{~mL})$ nodules [73].

No major complications, such as permanent recurrent laryngeal nerve palsy or skin burns, were reported in the above studies. Common side effects were pain, usually 
rapidly subsiding after treatment, skin redness, and protracted subcutaneous swelling [70-72]. In a retrospective study, however, unilateral vocal cord palsy was reported in 4 out of $103(4 \%)$ cases [74] and the complications were related to a $<1.1 \mathrm{~cm}$ distance between the HIFU focus point and the trachea-esophageal groove [74]. Thyroid function appears unaffected by the HIFU treatment [75].

Studies addressing QoL changes are limited. In a retrospective non-randomized trial, HIFU treatment, as opposed to surgery, was associated with shorter hospital stay, lower cost and better post-procedural quality of the voice [76].

\section{Comparison of Outcomes of Different TA}

Techniques for Benign Solid Non-Functioning

Thyroid Nodules

Studies comparing RFA and LTA suggest a nearly similar clinical efficacy and safety of the 2 techniques. Notably, the outcomes of these operator-dependent techniques are markedly influenced by the specific skill and the training period of the physicians who perform minimally invasive procedures. A retrospective multicenter study compared data obtained from 138 patients treated by LTA and 138 patients treated by RFA, after propensity score matching [77]. Mean volume reductions at 6 and 12 months were not statistically different between the RFA- and the LTA-treated group [77]. Two systematic reviews covering a total of 184 and 1,186 patients, respectively, showed a moderate superiority of RFA in terms of nodule volume reduction. In the first study, a greater 6-month mean volume change (77.8 vs. $49.5 \%$ ) was reported after RFA as compared to LTA [78]. Similarly, in the other meta-analysis, at 12 and 24 months RFA showed a greater VRR than LTA ( 75 vs. $52 \%$ and 87 vs. $45 \%$, respectively) [49]. In a paper based on a direct comparison of RFA and LTA, both performed by the same skilled operators, the techniques demonstrated similar technique efficacy and rate of complications [79]. Finally, a recent single-use, randomized, open-label, parallel trial compared the outcomes of RFA and LA groups. Six months after treatment, the nodule volume reduction was $64.3 \%$ in the RFA group and $53.2 \%$ in the LTA group, while no significant difference was observed between RFA and LTA for the improvement of compressive symptoms and cosmetic score [80].

In a prospective non-randomized multicenter study of 1,252 patients treated with MWA or RFA, the 2 techniques appeared similarly effective, with a non-significantly greater nodule VRR at 6 months in the RFA group (65 vs. $58 \%$ ). MWA was also associated with a slightly higher complication rate than RFA (7 vs. 5\%, respective- ly) [81]. These results have been confirmed by a retrospective study of 108 patients after propensity score adjustment [82].

There are neither prospective randomized nor propensity score-matched trials evaluating the efficacy and tolerability of HIFU in comparison with the other TA techniques. In a small uncontrolled series of patients, HIFU, RFA, and MWA showed a comparable nodule volume reduction at 3 months $(48,50$, and $44 \%$, respectively) [83]. However, the results were partly biased by differences in baseline volume of the nodules, which were significantly smaller in the HIFU group [83].

Recommendation 9. Based on direct comparison studies, and balance between efficacy and side-effects, LTA and RFA are recommended as the first-line TA treatment modalities $(1, \varnothing \varnothing \varnothing \mathrm{O})$.

Recommendation 10. Based on studies to date, MWA should at present be considered a second-line TA procedure in patients who are not suitable for or decline other TA procedures, or for participants in protocolled clinical studies $(1, \varnothing \varnothing О О)$.

Recommendation 11. Based on its lower efficacy, higher cost, and limited reported trial evidence, as compared to RFA and LTA, HIFU should be considered only for selected nodules in patients who are not suitable for or decline other TA procedures, and for participants in protocolled studies $(1, \varnothing \varnothing О O)$.

Recommendation 12. In multinodular goiters, due to lack of evidence of efficacy and the expected need of repeat treatment, TA should be restricted to patients with a well-defined dominant nodule or those who are not candidates for thyroid surgery or radioactive iodine treatment, as a palliative therapy option $(1, \varnothing \varnothing O O)$.

\section{Cystic Nodules}

EA is recommended as the first-line treatment for benign cystic thyroid nodules [2], based on retrospective and prospective studies having shown nodule volume reduction after EA ranging from 50 to $98 \%$, paralleled by improvement in local symptoms $[84,85]$. These favorable outcomes persist 5 years post-treatment [85]. The main factors negatively influencing the technical efficacy of EA are the number of previous interventions, increasing size of the solid as well as the cystic component, multilocularity, initial nodule volume $>10 \mathrm{~mL}$, and increasing vascularization of the lesion [85]. Based on the aforementioned, TA is considered as a potential treatment only for selected predominantly cystic nodules.

\section{Laser}

LTA, as well as RFA and MWA, demand to be applied after drainage of the fluid component of the cystic lesion, usually performed during the same session [86]. Studies specifically dedicated to LTA treatment of cystic thyroid nodules are limited. In a prospective randomized trial in 44 patients [86], LTA achieved remission, defined as the 
reduction of cyst volume to $\leq 1 \mathrm{~mL}$, in $68 \%$ of patients vs. $18 \%$ in the control group. LTA treatment also achieved a significant reduction of the solid part of the nodules, while the solid component was unchanged in the control group. The combined use of ethanol and LTA has been demonstrated to be effective in very large cystic nodules [87]. Long-term follow-up demonstrated a maintained efficacy of this approach in the majority of treated patients [88].

\section{Radiofrequency}

Most series employing RFA include both solid and cystic nodules, while only few studies specifically address the use of RFA in cystic nodules. In a trial in 57 patients either treated with EA or RFA, the latter resulted in a significantly higher reduction of thyroid nodule volume and symptom scores [89]. Two prospective randomized trials comparing the effects of ethanol versus RFA treatment in 50 patients with predominantly cystic nodules, showed similar technical efficacy, with a 93 and $87 \%$ volume reduction in RFAand EA-treated nodules, respectively, at 6-month follow-up $[90,91]$. In all the above-quoted studies, EA and RFA demonstrated nearly similar efficacy, reinforcing EA as the firstline therapy for benign cystic nodules due to its lower cost. However, EA and RFA may be effectively combined to implement an otherwise incomplete treatment [92].

\section{Microwave Ablation}

As for RFA, the majority of studies using MWA include both cystic and solid nodules, and no trials have been specifically devoted to cystic thyroid lesions. In 474 benign thyroid nodules undergoing MWA, VRR in predominantly cystic nodules ( $95 \%$ at 12 months) was significantly higher than in solid nodules [22]. This has been confirmed in a prospective study reporting a $92 \%$ volume reduction at 12 months [68].

\section{High-Intensity Focused Ultrasound}

HIFU is based on a non-invasive approach that does not allow the drainage of fluid collections. There are no relevant studies reporting on fluid removal followed by HIFU treatment as, even after drainage, a liquid component that may hamper US efficacy usually persists within the solid component of the cystic lesion.

Recommendation 13. Because of higher cost and complexity, as compared to aspiration and EA, TA procedures are not recommended as a first line treatment for pure or dominantly cystic thyroid lesions (1, ØØØО).

Recommendation 14. LTA and RFA should be considered therapeutic options for cystic lesions that relapse after EA and for those that would remain symptomatic due to a large residual solid component $(1, \varnothing \varnothing \varnothing 0)$.

ETA Image-Guided Thyroid Ablation Guideline
Benign Autonomously Functioning Thyroid Nodules

Laser Thermal Ablation and Radiofrequency

Ablation

Data on TA in AFTNs are mostly based on LTA [38, 93, 94] and RFA $[95,96]$ treatment. Overall, the mean technical efficacy, defined for AFTN as restoration of normal thyroid function associated with a $\geq 80 \%$ reduction of initial volume, is around $50 \%$ at 12 months, but the larger the nodule the poorer the likelihood of achieving durable control of thyroid function. Based on the available data, TA may achieve near-complete normalization of serum thyroid hormones in small size (e.g., $\leq 10 \mathrm{~mL}$ ) AFTN, accompanied by a substantial $(>80 \%)$ volume reduction, while thyroid function is controlled only in a small fraction of larger AFTN $[94,97]$. Thus, TA may be best employed for patients with small AFTNs who decline or are not suitable - due to iodine repletion, comorbidities or pregnancy - for RAI therapy or thyroid surgery.

In a prospective trial, patients with large $(>10 \mathrm{~mL})$ hyperfunctioning thyroid nodules, treated either with RAI alone or with LTA followed after 1 month by RAI, demonstrated a greater and more rapid improvement of local symptoms after the combined treatment [98]. Moreover, nodule volume reduction was more pronounced, and the dose of administered RAI was significantly lower [98]. Therefore, TA could be used for selected large-size AFTNs to obtain a volume reduction prior to RAI treatment [94, 98].

A prospective study employing a 12-item Short Form Health Survey questionnaire demonstrated a comparable improvement in HRQoL in patients with AFTN offered either lobectomy or LTA followed by RAI [99].

\section{High-Intensity Focused Ultrasound}

HIFU is less effective than RAI for control of hyperfunctioning nodules. A prospective trial in 2 cohorts treated either with HIFU or RAI demonstrated that euthyroidism at 12 months was obtained in $94 \%$ of the RAItreated versus $53 \%$ of the HIFU-treated patients [100].

\section{Microwave Ablation}

There are no relevant studies specifically addressing the efficacy and safety of MWA for the treatment of AFTN.

Recommendation 15. We recommend against TA as first-line treatment for large AFTN. Due to the low rate of restoration of normal thyroid function, TA should be considered only for patients who decline or are not candidates for RAI therapy or surgery (1, ØØØО).

Recommendation 16. TA should be considered in young patients with small AFTN and incomplete suppression of perinodu-

Eur Thyroid J 2020;9:172-185 
lar thyroid tissue due to the higher probability of normalization of thyroid function and the advantage of avoiding irradiation and restricting the risk of late hypothyroidism $(1, \varnothing \varnothing \mathrm{\varnothing O})$.

Recommendation 17. Treatment with a combination of LTA or RFA and RAI may be considered in selected patients with large AFTN that cause local pressure symptoms in order to achieve a more rapid volume reduction and use of a lower RAI activity (2, Ø๐ОО).

\section{Concluding Remarks}

Currently, US-guided TA procedures may be considered for selected cases as alternative options to the wellestablished treatments. TA can change the natural history of benign thyroid lesions that keep growing over time in order to prevent or control symptoms without causing hypothyroidism and to reduce risk of surgical complications. Notably, after nearly 20 years of clinical use, there is no evidence of TA techniques causing thyroid neoplasia $[101,102]$.

In the frame of a patient-tailored approach, the following factors need consideration when contemplating the use of a TA procedure for thyroid nodules in young and adult patients:

- Risk of malignancy should be reliably ruled out and the advantages and disadvantages of all available options weighed in a dialogue with the patient.

- TA procedures should not be used for decreasing the volume of asymptomatic thyroid nodules, unless there is documented and clinically significant growth over time.

- In case of cystic (or predominantly cystic) symptomatic nodules, EA is to be preferred as the most effective, rapid, and least expensive treatment. TA may be considered for cystic lesions that relapse after EA or for those with a residual solid nodule following EA.

- TA should aim at the most complete destruction of the targeted nodule in order to alleviate symptoms and prevent regrowth while maintaining safe procedures and minimizing the risk of side effects. In general, spongiform and complex nodules are better candidates for TA compared to solid compact nodules.
- TA is associated with a low rate of major and minor complications, but adverse effects are potentially severe. Therefore, the operators need a dedicated training in image-guided thyroid therapeutic procedures.

- TA effects may be stable for years. However, nodule re-growth may occur, and a decision to repeat treatment or offer a different treatment option, for example surgery, needs to be reached together with the patient.

- Among the available TA techniques, LTA and RFA have long been used by several centers, providing robust and consistent clinical results. MWA has only recently been used for treatment of thyroid nodules and needs further validation, as does HIFU.

\section{Acknowledgments}

We are indebted to the many ETA members who dedicated their time to improve these guidelines.

\section{Statement of Ethics}

This work was conducted ethically in accordance with the World Medical Association Declaration of Helsinki. According to Danish law, this type of research does not need Ethical Committee approval.

\section{Disclosure Statement}

The authors have nothing to disclose.

\section{Funding Sources}

There are no funding sources to declare.

\section{Author Contributions}

All authors contributed to the idea, gathered the information, interpreted the data, and wrote and accepted the final version of the manuscript.

\section{References}

1 Hegedüs L. Clinical practice. The thyroid nodule. N Engl J Med. 2004 Oct;351(17):1764-71.

2 Gharib H, Papini E, Garber JR, Duick DS, Harrell RM, Hegedüs L, et al.; AACE/ACE/AME Task Force on Thyroid Nodules. American Association of Clinical Endocrinologists, American College Of Endocrinology, and Associazione Medici Endocrinologi Medical Guidelines for Clinical Practice for the Diagnosis and Management of Thyroid Nodules-2016 Update. Endocr Pract. 2016 May;22(5):622-39.

3 Haugen BR, Alexander EK, Bible KC, Doherty GM, Mandel SJ, Nikiforov YE, et al. 2015 American Thyroid Association management guidelines for adult patients with thyroid nodules and differentiated thyroid cancer: the
American Thyroid Association guidelines task force on thyroid nodules and differentiated thyroid cancer. Thyroid. 2016 Jan;26(1):1-133.

4 Mathonnet M, Cuerq A, Tresallet C, Thalabard JC, Fery-Lemonnier E, Russ G, et al. What is the care pathway of patients who undergo thyroid surgery in France and its potential pitfalls? A national cohort.BMJOpen.2017 Apr;7(4):e013589. 
5 Bartsch DK, Dotzenrath C, Vorländer C, Zielke A, Weber T, Buhr HJ, et al. Current Practice of Surgery for Benign Goitre-An Analysis of the Prospective DGAV StuDoQ|Thyroid Registry. J Clin Med. 2019 Apr;8(4):477-86.

6 Gharib H, Hegedüs L, Pacella CM, Baek JH, Papini E. Clinical review: Nonsurgical, image-guided, minimally invasive therapy for thyroid nodules. J Clin Endocrinol Metab. 2013 Oct;98(10):3949-57.

7 Papini E, Pacella CM, Misischi I, Guglielmi R, Bizzarri G, Døssing $\mathrm{H}$, et al. The advent of ultrasound-guided ablation techniques in nodular thyroid disease: towards a patient-tailored approach. Best Pract Res Clin Endocrinol Metab. 2014 Aug;28(4):601-18.

8 Mauri G, Sconfienza LM. Percutaneous ablation holds the potential to substitute for surgery as first choice treatment for symptomatic benign thyroid nodules. Int J Hyperthermia. 2017 May;33(3):301-2.

9 Dietrich CF, Müller T, Bojunga J, Dong Y, Mauri G, Radzina M, et al. Statement and recommendations on interventional ultrasound as a thyroid diagnostic and treatment procedure. Ultrasound Med Biol. 2018 Jan;44(1): 14-36.

10 Kim JH, Baek JH, Lim HK, Ahn HS, Baek SM, Choi YJ, et al.; Guideline Committee for the Korean Society of Thyroid Radiology (KSThR) and Korean Society of Radiology. 2017 Thyroid radiofrequency ablation guideline: Korean Society of Thyroid Radiology. Korean J Radiol. 2018 Jul-Aug;19(4):632-55.

11 Papini E, Pacella CM, Solbiati LA, Achille G, Barbaro D, Bernardi S, et al. Minimally-invasive treatments for benign thyroid nodules: a Delphi-based consensus statement from the Italian minimally-invasive treatments of the thyroid (MITT) group. Int J Hyperthermia. 2019;36(1):376-82.

12 Dobnig $H$, Zechmann W, Hermann $M$, Lehner M, Heute D, Mirzaei S, et al. Radiofrequency ablation of thyroid nodules: "Good Clinical Practice Recommendations" for Austria: An interdisciplinary statement from the following professional associations: Austrian Thyroid Association (ÖSDG), Austrian Society for Nuclear Medicine and Molecular Imaging (OGNMB), Austrian Society for Endocrinology and Metabolism (ÖGES), Surgical Endocrinology Working Group (ACE) of the Austrian Surgical Society (OEGCH). Wien Med Wochenschr. 2020 Feb;170(1-2):6-14.

13 Hegedüs L, Frasoldati A, Negro R, Papini E. European Thyroid Association Survey on Use of Minimally Invasive Techniques for Thyroid Nodules. Eur Thyroid J. DOI: 10.1159/000506513.

14 Mauri G, Pacella CM, Papini E, Solbiati L, Goldberg SN, Ahmed M, et al. Image-Guided Thyroid Ablation: Proposal for Standardization of Terminology and Reporting Criteria. Thyroid. 2019 May;29(5):611-8.

15 Russ G, Bonnema SJ, Erdogan MF, Durante C, Ngu R, Leenhardt L. European Thyroid Association Guidelines for Ultrasound Malig- nancy Risk Stratification of Thyroid Nodules in Adults: the EU-TIRADS. Eur Thyroid J. 2017 Sep;6(5):225-37.

16 Cibas ES, Ali SZ. The 2017 Bethesda System for Reporting Thyroid Cytopathology. Thyroid. 2017 Nov;27(11):1341-6.

17 Swiglo BA, Murad MH, Schünemann HJ, Kunz R, Vigersky RA, Guyatt GH, et al. A case for clarity, consistency, and helpfulness: stateof-the-art clinical practice guidelines in endocrinology using the grading of recommendations, assessment, development, and evaluation system. J Clin Endocrinol Metab. 2008 Mar;93(3):666-73.

18 Park HS, Baek JH, Park AW, Chung SR, Choi YJ, Lee JH. Thyroid Radiofrequency Ablation: Updates on Innovative Devices and Techniques. Korean J Radiol. 2017 Jul-Aug; 18(4): 615-23.

19 Kohlhase KD, Korkusuz Y, Gröner D, Erbelding C, Happel C, Luboldt W, et al. Bipolar radiofrequency ablation of benign thyroid nodules using a multiple overlapping shot technique in a 3-month follow-up. Int $\mathrm{J} \mathrm{Hy}$ perthermia. 2016 Aug;32(5):511-6.

20 Yue W, Wang S, Wang B, Xu Q, Yu S, Yonglin $\mathrm{Z}$, et al. Ultrasound guided percutaneous microwave ablation of benign thyroid nodules: safety and imaging follow-up in 222 patients. Eur J Radiol. 2013 Jan; 82(1):e11-6

21 Wu W, Gong X, Zhou Q, Chen X, Chen X, Shi $B$. US-guided percutaneous microwave ablation for the treatment of benign thyroid nodules. Endocr J. 2017 Nov;64(11):1079-85.

22 Liu YJ, Qian LX, Liu D, Zhao JF. Ultrasoundguided microwave ablation in the treatment of benign thyroid nodules in 435 patients. Exp Biol Med (Maywood). 2017 Sep;242(15): 1515-23.

23 Korkusuz H, Sennert M, Fehre N, Happel C, Grünwald F. Local thyroid tissue ablation by high-intensity focused ultrasound: effects on thyroid function and first human feasibility study with hot and cold thyroid nodules. Int J Hyperthermia. 2014 Nov;30(7):480-5.

24 Kovatcheva RD, Vlahov JD, Stoinov JI, Zaletel K. Benign Solid Thyroid Nodules: US-guided High-Intensity Focused Ultrasound Ablation-Initial Clinical Outcomes. Radiology. 2015 Aug;276(2):597-605.

25 Sillery JC, Reading CC, Charboneau JW, Henrichsen TL, Hay ID, Mandrekar JN. Thyroid follicular carcinoma: sonographic features of 50 cases. AJR Am J Roentgenol. 2010 Jan;194(1):44-54.

26 Park JW, Kim DW, Kim D, Baek JW, Lee YJ, Baek HJ. Korean Thyroid Imaging Reporting and Data System features of follicular thyroid adenoma and carcinoma: a single-center study. Ultrasonography. 2017 Oct;36(4):34954.

27 Sangalli G, Serio G, Zampatti C, Bellotti M, Lomuscio G. Fine needle aspiration cytology of the thyroid: a comparison of 5469 cytological and final histological diagnoses. Cytopathology. 2006 Oct;17(5):245-50.
28 Mehanna R, Murphy M, McCarthy J, O’Leary G, Tuthill A, Murphy MS, et al. False negatives in thyroid cytology: impact of large nodule size and follicular variant of papillary carcinoma. Laryngoscope. 2013 May; 123(5): 1305-9.

29 Trimboli P, Ngu R, Royer B, Giovanella L, Bigorgne C, Simo R, et al. A multicentre validation study for the EU-TIRADS using histological diagnosis as a gold standard. Clin Endocrinol (Oxf). 2019 Aug;91(2):340-7.

30 Eng OS, Potdevin L, Davidov T, Lu SE, Chen C, Trooskin SZ. Does nodule size predict compressive symptoms in patients with thyroid nodules? Gland Surg. 2014;3:232-6.

31 Hegedüs L, Bonnema SJ. Approach to management of the patient with primary or secondary intrathoracic goiter. J Clin Endocrinol Metab. 2010 Dec;95(12):5155-62.

32 Maher DI, Goare S, Forrest E, Grodski S, Serpell JW, Lee JC. Routine preoperative laryngoscopy for thyroid surgery is not necessary without risk factors. Thyroid. 2019 Nov; 29(11):1646-52.

33 Bonnema SJ, Hegedüs L. Radioiodine therapy in benign thyroid diseases: effects, side effects, and factors affecting therapeutic outcome. Endocr Rev. 2012 Dec;33(6):920-80.

34 Xiaoyin T, Ping L, Dan C, Min D, Jiachang C, Tao W, et al. Risk Assessment and Hydrodissection Technique for Radiofrequency Ablation of Thyroid Benign Nodules. J Cancer. 2018 Aug;9(17):3058-66.

35 Papini E, Bizzarri G, Bianchini A, Guglielmi R, Graziano F, Lonero F, et al. Contrast-enhanced ultrasound in the management of thyroid nodules. In: Baskin HJ, Duick DS, Levine RA, editors. Thyroid Ultrasound and Ultrasound-Guided FNA. 2nd ed. New York: Springer; 2008. p. 151-71.

36 Sim JS, Baek JH, Lee J, Cho W, Jung SI. Radiofrequency ablation of benign thyroid nodules: depicting early sign of regrowth by calculating vital volume. Int J Hyperthermia. 2017 Dec; 33(8):905-10.

37 Wang B, Han ZY, Yu J, Cheng Z, Liu F, Yu XL, et al. Factors related to recurrence of the benign non-functioning thyroid nodules after percutaneous microwave ablation. Int J Hyperthermia. 2017 Jun;33(4):459-64.

38 Gambelunghe G, Stefanetti E, Colella R, Monacelli M, Avenia N, De Feo P. A single session of laser ablation for toxic thyroid nodules: three-year follow-up results. Int J Hyperthermia. 2018 Aug;34(5):631-5.

39 Sim JS, Baek JH. Long-Term Outcomes Following Thermal Ablation of Benign Thyroid Nodules as an Alternative to Surgery: The Importance of Controlling Regrowth. Endocrinol Metab (Seoul). 2019 Jun;34(2):11723.

40 Zhao CK, Xu HX, Lu F, Sun LP, He YP, Guo $\mathrm{LH}$, et al. Factors associated with initial incomplete ablation for benign thyroid nodules after radiofrequency ablation: first results of CEUS evaluation. Clin Hemorheol Microcirc. 2017;65(4):393-405. 
41 Døssing H, Bennedbaek FN, Hegedüs L. Effect of ultrasound-guided interstitial laser photocoagulation on benign solitary solid cold thyroid nodules - a randomised study. Eur J Endocrinol. 2005 Mar;152(3):341-5.

42 Papini E, Guglielmi R, Bizzarri G, Graziano F, Bianchini A, Brufani C, et al. Treatment of benign cold thyroid nodules: a randomized clinical trial of percutaneous laser ablation versus levothyroxine therapy or follow-up. Thyroid. 2007 Mar; 17(3):229-35.

43 Papini E, Rago T, Gambelunghe G, Valcavi R, Bizzarri G, Vitti P, et al. Long-term efficacy of ultrasound-guided laser ablation for benign solid thyroid nodules. Results of a three-year multicenter prospective randomized trial. J Clin Endocrinol Metab. 2014 Oct;99(10): 3653-9.

44 Pacella CM, Mauri G, Achille G, Barbaro D, Bizzarri G, De Feo P, et al. Outcomes and risk factors for complications of laser ablation for thyroid nodules: a multicenter study on 1531 patients. J Clin Endocrinol Metab. 2015 Oct; 100(10):3903-10.

45 Achille G, Zizzi S, Di Stasio E, Grammatica A, Grammatica L. Ultrasound-guided percutaneous laser ablation in treating symptomatic solid benign thyroid nodules: our experience in 45 patients. Head Neck. 2016 May;38(5): $677-82$.

46 Valcavi R, Riganti F, Bertani A, Formisano D, Pacella CM. Percutaneous laser ablation of cold benign thyroid nodules: a 3-year followup study in 122 patients. Thyroid. 2010 Nov; 20(11):1253-61.

47 Døssing H, Bennedbæk FN, Hegedüs L. Long-term outcome following interstitial laser photocoagulation of benign cold thyroid nodules. Eur J Endocrinol. 2011 Jul;165(1): 123-8.

48 Negro R, Salem TM, Greco G. Laser ablation is more effective for spongiform than solid thyroid nodules. A 4-year retrospective follow-up study. Int J Hyperthermia. 2016 Nov; 32(7):822-8.

49 Trimboli P, Castellana M, Sconfienza LM, Virili C, Pescatori LC, Cesareo R, et al. Efficacy of thermal ablation in benign non-functioning solid thyroid nodule: A systematic review and meta-analysis. Endocrine. 2020 Jan; 67(1):35-43.

50 Sacks D, McClenny TE, Cardella JF, Lewis CA. Society of Interventional Radiology clinical practice guidelines. J Vasc Interv Radiol. 2003 Sep;14(9 Pt 2):S199-202.

51 Watt T, Hegedüs L, Groenvold M, Bjorner JB, Rasmussen AK, Bonnema SJ, et al. Validity and reliability of the novel thyroid-specific quality of life questionnaire, ThyPRO. Eur J Endocrinol. 2010 Jan;162(1):161-7.

52 Watt T, Bjorner JB, Groenvold M, Cramon P, Winther KH, Hegedüs L, et al. Development of a short version of the thyroid-related patient-reported outcome ThyPRO. Thyroid. 2015 Oct;25(10):1069-79.

53 Oddo S, Felix E, Mussap M, Giusti M. Quality of life in patients treated with percutaneous laser ablation for non-functioning benign thyroid nodules: a prospective single-center study. Korean J Radiol. 2018 Jan-Feb;19(1): 175-84.

54 Chen F, Tian G, Kong D, Zhong L, Jiang T. Radiofrequency ablation for treatment of benign thyroid nodules: A PRISMA-compliant systematic review and meta-analysis of outcomes. Medicine (Baltimore). 2016 Aug; 95(34):e4659.

55 Dobnig H, Amrein K. Monopolar Radiofrequency Ablation of Thyroid Nodules: A Prospective Austrian Single-Center Study. Thyroid. 2018 Apr;28(4):472-80.

56 Deandrea M, Sung JY, Limone P, Mormile A, Garino F, Ragazzoni F, et al. Efficacy and safety of radiofrequency ablation versus observation for non functioning benign thyroid nodules: a randomized controlled international collaborative trial. Thyroid. 2015 Aug;25(8): 890-6.

57 Cesareo R, Pasqualini V, Simeoni C, Sacchi M, Saralli E, Campagna G, et al. Prospective study of effectiveness of ultrasound-guided radiofrequency ablation versus control group in patients affected by benign thyroid nodules. J Clin Endocrinol Metab. 2015 Feb; 100(2):460-6.

58 Deandrea M, Trimboli P, Garino F, Mormile A, Magliona G, Ramunni MJ, et al. Long term efficacy of a single session RFA of benign thyroid nodules: a longitudinal 5-year observational study. J Clin Endocrinol Metab. 2019 Sep;104(9):3751-6.

59 Deandrea M, Garino F, Alberto M, Garberoglio R, Rossetto R, Bonelli N, et al. Radiofrequency ablation for benign thyroid nodules according to different ultrasound features: an Italian multicentre prospective study. Eur J Endocrinol. 2019 Jan;180(1):7987.

60 Guang Y, He W, Luo Y, Zhang H, Zhang Y, Ning B, et al. Patient satisfaction of radiofrequency ablation for symptomatic benign solid thyroid nodules: our experience for 2-year follow up. BMC Cancer. 2019 Feb; 19(1): 147.

61 Baek JH, Lee JH, Sung JY, Bae JI, Kim KT, Sim J, et al.; Korean Society of Thyroid Radiology. Complications encountered in the treatment of benign thyroid nodules with US-guided radiofrequency ablation: a multicenter study. Radiology. 2012 Jan;262(1): 335-42.

62 Chung SR, Suh CH, Baek JH, Park HS, Choi YJ, Lee JH. Safety of radiofrequency ablation of benign thyroid nodules and recurrent thyroid cancers: a systematic review and metaanalysis. Int J Hyperthermia. 2017 Dec;33(8): 920-30.

63 Bernardi S, Dobrinja C, Carere A, Giudici F, Calabrò V, Zanconati F, et al. Patient satisfaction after thyroid RFA versus surgery for benign thyroid nodules: a telephone survey. Int J Hyperthermia. 2018;35(1):150-8.

64 Yue WW, Wang SR, Li XL, Xu HX, Lu F, Sun LP, et al. Quality of Life and cost-effectiveness of radiofrequency ablation versus open surgery for benign thyroid nodules: a retrospective cohort study. Sci Rep. 2016 Nov;6(1): 37838.

65 Jin H, Fan J, Liao K, He Z, Li W, Cui M. A propensity score matching study between ultrasound-guided percutaneous microwave ablation and conventional thyroidectomy for benign thyroid nodules treatment. Int $\mathrm{J} \mathrm{Hy}$ perthermia. 2018;35(1):232-8.

66 Zheng BW, Wang JF, Ju JX, Wu T, Tong G, Ren J. Efficacy and safety of cooled and uncooled microwave ablation for the treatment of benign thyroid nodules: a systematic review and meta-analysis. Endocrine. 2018 Nov;62(2):307-17.

67 Mader OM, Tanha NF, Mader A, Happel C, Korkusuz Y, Grünwald F. Comparative study evaluating the efficiency of cooled and uncooled single-treatment MWA in thyroid nodules after a 3-month follow up. Eur J Radiol Open. 2017 Feb;4:4-8.

68 Zhi X, Zhao N, Liu Y, Liu JB, Teng C, Qian L. Microwave ablation compared to thyroidectomy to treat benign thyroid nodules. Int J Hyperthermia. 2018 Aug;34(5):644-52.

69 Yan J, Qiu T, Lu J, Wu Y, Yang Y. Microwave ablation induces a lower systemic stress response in patients than open surgery for treatment of benign thyroid nodules. Int J Hyperthermia. 2018 Aug;34(5):606-10.

70 Lang BH, Wu AL. High intensity focused ultrasound (HIFU) ablation of benign thyroid nodules - a systematic review. J Ther Ultrasound. 2017 May;5(1):11.

71 Trimboli P, Pelloni F, Bini F, Marinozzi F, Giovanella L. High-intensity focused ultrasound (HIFU) for benign thyroid nodules: 2-year follow-up results. Endocrine. 2019 Aug;65(2):312-7.

72 Lang BH, Woo YC, Chiu KW. Two-year efficacy of single-session high-intensity focused ultrasound (HIFU) ablation of benign thyroid nodules. Eur Radiol. 2019 Jan;29(1):93-101.

73 Sennert M, Happel C, Korkusuz Y, Grünwald F, Polenz B, Gröner D. Further investigation on high-intensity focused ultrasound(HIFU) treatment for thyroid nodules: effectiveness related to baseline volumes. Acad Radiol. 2018 Jan;25(1):88-94.

74 Lang BH, Woo YC, Chiu KW. Vocal cord paresis following single-session high intensity focused ablation (HIFU) treatment of benign thyroid nodules: incidence and risk factors. Int J Hyperthermia. 2017 Dec;33(8): 888-94.

75 Lang BH, Woo YC, Chiu KW. High-intensity focused ablation (HIFU) of single benign thyroid nodule rarely alters underlying thyroid function. Int J Hyperthermia. 2017 Dec;33(8): $875-81$

76 Lang BH, Wong CK, Ma EP. Single-session high intensity focused ablation (HIFU) versus open cervical hemithyroidectomy for benign thyroid nodule: analysis on early efficacy, safety and voice quality. Int J Hyperthermia. 2017 Dec;33(8):868-74. 
77 Pacella CM, Mauri G, Cesareo R, Paqualini V, Cianni R, De Feo P, et al. A comparison of laser with radiofrequency ablation for the treatment of benign thyroid nodules: a propensity score matching analysis. Int $J$ Hyperthermia. 2017 Dec;33(8):911-9.

78 Ha EJ, Baek JH, Kim KW, Pyo J, Lee JH, Baek $\mathrm{SH}$, et al. Comparative efficacy of radiofrequency and laser ablation for the treatment of benign thyroid nodules: systematic review including traditional pooling and bayesian network meta-analysis. J Clin Endocrinol Metab. 2015 May;100(5):1903-11.

79 Ben Hamou A, Ghanassia E, Espiard S, Abi Rached H, Jannin A, Correas JM, et al. Safety and efficacy of thermal ablation (radiofrequency and laser): should we treat all types of thyroid nodules? $\uparrow$. Int J Hyperthermia. 2019; 36(1):666-76.

80 Cesareo R, Pacella CM, Pasqualini V, Campagna $\mathrm{G}$, Iozzino M, Gallo A, et al. Laser Ablation Versus Radiofrequency Ablation for Benign Non-Functioning Thyroid Nodules: SixMonth Results of a Randomized, Parallel, Open-Label, Trial (LARA Trial). Thyroid. 2020, Epub ahead of print.

81 Cheng Z, Che Y, Yu S, Wang S, Teng D, Xu H, et al. US-guided percutaneous radiofrequency versus microwave ablation for benign thyroid nodules: a prospective multicenter study. Sci Rep. 2017 Aug;7(1):9554.

82 Yue WW, Wang SR, Lu F, Sun LP, Guo LH, Zhang YL, et al. Radiofrequency ablation vs. microwave ablation for patients with benign thyroid nodules: a propensity score matching study. Endocrine. 2017 Feb;55(2):485-95.

83 Korkusuz Y, Gröner D, Raczynski N, Relin O, Kingeter Y, Grünwald F, et al. Thermal ablation of thyroid nodules: are radiofrequency ablation, microwave ablation and high intensity focused ultrasound equally safe and effective methods? Eur Radiol. 2018 Mar;28(3): 929-35.
84 Bennedbaek FN, Hegedüs L. Percutaneous ethanol injection therapy in benign solitary solid cold thyroid nodules: a randomized trial comparing one injection with three injections. Thyroid. 1999 Mar;9(3):225-33.

85 Guglielmi R, Pacella CM, Bianchini A, Bizzarri G, Rinaldi R, Graziano FM, et al. Percutaneous ethanol injection treatment in benign thyroid lesions: role and efficacy. Thyroid. 2004 Feb;14(2):125-31.

86 Døssing H, Bennedbaek FN, Hegedus L. Interstitial laser photocoagulation (ILP) of benign cystic thyroid nodules - a prospective randomized trial. J Clin Endocrinol Metab. 2013 Jul;98:E1213-17.

87 Negro R, Greco G. Percutaneous Ethanol Injection in Combination with Laser Ablation for a $100 \mathrm{ml}$ Partially Cystic Thyroid Nodule. Case Rep Endocrinol. 2018 Feb;2018:8046378.

88 Døssing H, Bennedbæk FN, Hegedüs L. Long-term outcome following laser therapy of benign cystic-solid thyroid nodules. Endocr Connect. 2019 Jul;8(7):846-52.

89 Sung JY, Kim YS, Choi H, Lee JH, Baek JH. Optimum first-line treatment technique for benign cystic thyroid nodules: ethanol ablation or radiofrequency ablation? AJR Am J Roentgenol. $2011 \mathrm{Feb}$;196(2):W210-4.

90 Sung JY, Baek JH, Kim KS, Lee D, Yoo H, Kim JK, et al. Single-session treatment of benign cystic thyroid nodules with ethanol versus radiofrequency ablation: a prospective randomized study. Radiology. 2013 Oct;269(1):293300.

91 Baek JH, Ha EJ, Choi YJ, Sung JY, Kim JK, Shong YK. Radiofrequency versus ethanol ablation for treating predominantly cystic thyroid nodules: a randomized clinical trial. Korean J Radiol. 2015 Nov-Dec;16(6):1332-40.

92 Park HS, Baek JH, Choi YJ, Lee JH. Innovative Techniques for Image-Guided Ablation of Benign Thyroid Nodules: Combined Ethanol and Radiofrequency Ablation. Korean J Radiol. 2017 May-Jun;18(3):461-9.

93 Døssing H, Bennedbaek FN, Bonnema SJ, Grupe P, Hegedüs L. Randomized prospective study comparing a single radioiodine dose and a single laser therapy session in autonomously functioning thyroid nodules. Eur J Endocrinol. 2007 Jul;157(1):95-100.
94 Pacella CM, Mauri G. Is there a role for minimally invasive thermal ablations in the treatment of autonomously functioning thyroid nodules? Int J Hyperthermia. 2018 Aug; 34(5):636-8.

95 Sung JY, Baek JH, Jung SL, Kim JH, Kim KS, Lee $\mathrm{D}$, et al. Radiofrequency ablation for autonomously functioning thyroid nodules: a multicenter study. Thyroid. 2015 Jan;25(1): 112-7.

96 Bernardi S, Stacul F, Michelli A, Giudici F, Zuolo G, de Manzini N, et al. 12-month efficacy of a single radiofrequency ablation on autonomously functioning thyroid nodules. Endocrine. 2017 Sep;57(3):402-8.

97 Cesareo R, Naciu AM, Iozzino M, Pasqualini V, Simeoni C, Casini A, et al. Nodule size as predictive factor of efficacy of radiofrequency ablation in treating autonomously functioning thyroid nodules. Int J Hyperthermia. 2018 Aug;34(5):617-23.

98 Chianelli M, Bizzarri G, Todino V, Misischi I, Bianchini A, Graziano F, et al. Laser ablation and 131-iodine: a 24-month pilot study of combined treatment for large toxic nodular goiter. J Clin Endocrinol Metab. 2014 Jul; 99(7):E1283-6.

99 Negro R, Greco G. Quality of life and outcomes in patients with a large toxic adenoma undergoing laser ablation plus radioiodine vs lobectomy. Int J Hyperthermia. 2019 Dec; 36(1):191-5.

100 Giovanella L, Piccardo A, Pezzoli C, Bini F, Ricci R, Ruberto T, et al. Comparison of high intensity focused ultrasound and radioiodine for treating toxic thyroid nodules. Clin Endocrinol (Oxf). 2018 Aug;89(2):219-25.

101 Ha SM, Shin JY, Baek JH, Song DE, Chung SR, Choi YJ, et al. Does Radiofrequency Ablation Induce Neoplastic Changes in Benign Thyroid Nodules: A Preliminary Study. Endocrinol Metab (Seoul). 2019 Jun;34(2): 169-78.

102 Dobrinja C, Bernardi S, Fabris B, Eramo R, Makovac P, Bazzocchi G, et al. Surgical and pathological changes after radiofrequency ablation of thyroid nodules. Int J Endocrinol. 2015;2015:576576.
ETA Image-Guided Thyroid Ablation Guideline
Eur Thyroid J 2020;9:172-185

DOI: $10.1159 / 000508484$ 